\title{
A Prática da Perícia Judicial em Processos de Propriedade Intelectual
}

\author{
The Practice of Judicial Expertise in Intellectual Property Lawsuits
}

\author{
Arnoldo Reinaldo Richter Filho ${ }^{1}$ \\ Marcelo Conrado ${ }^{1}$ \\ ${ }^{1}$ Universidade Federal de Paraná, Curitiba, PR, Brasil
}

\begin{abstract}
Resumo
Este artigo retrata a prática da perícia judicial com o objetivo de analisar como ocorre e qual sua importância em processos de propriedade intelectual, oportunizando a incorporação de conhecimentos específicos de temática peculiar, introduzindo-a aos leitores que esperam saber mais sobre o assunto e, eventualmente, queiram exercer atividades correlatas. Trata-se de uma pesquisa exploratória baseada em dados bibliométricos e documentais, com abordagem qualitativa, envolvendo estudo de casos. Versa sobre a caracterização da prova pericial, o papel e as atribuições do perito e o laudo pericial, além disso, seleciona alguns julgados, contextualizando as ações judiciais relativas a cada um deles, relatando aspectos relevantes em relação à prova pericial, tanto em caráter adequado, subsidiando a decisão judicial, quanto em questões equivocadas, levando à sua anulação. As considerações finais estão baseadas no aprendizado propiciado pelas análises práticas aliadas à revisão teórica.
\end{abstract}

Palavras-chave: Propriedade Intelectual. Prova Pericial. Perito.

\begin{abstract}
This article portrays the practice of judicial expertise in order to analyze how it occurs and what is its importance in intellectual property lawsuits, allowing the incorporation of specific knowledge of particular theme, introducing it to readers who hope to learn about the subject and, eventually, exercise related activities. It presents exploratory research based on bibliometric and documentary data, having qualitative approach, involving case studies. It deals with characterization of the expert evidence, role and attributions of the expert and its report, in addition, selects some judged, contextualizing legal actions related to each one, reporting relevant aspects in relation to the expert evidence, both in an appropriate character, subsidizing the judicial decision, as well as in wrong questions, leading to its annulment. The final considerations are based on the learning provided by the practical analysis combined with the theoretical review.
\end{abstract}

Keywords: Intellectual Property. Expert proof. Judicial Expert.

Área Tecnológica: Propriedade Intelectual. Direito. Engenharia. 


\section{Introdução}

Músicas, filmes, peças teatrais, obras de arte e literárias, trabalhos científicos, nomes comerciais, invenções, inovações, design, além de outras expressões da criatividade humana, podem ser convertidos em propriedade privada e protegidos por lei pelo sistema de propriedade intelectual.

No tocante a eventuais conflitos de interesse envolvendo tais apropriações, ações judiciais podem ser ajuizadas de maneira a buscar uma solução jurídica. Nesses casos, diferentes tipos de provas processuais podem ser produzidas, entre elas, a pericial.

O presente artigo retrata a produção da prova pericial em processos de propriedade intelectual, elencando requisitos básicos para atuar como perito, a importância da perícia dentro do processo judicial, o escopo do laudo, o papel do expert, entre outros. Também são estudados alguns julgados enfatizando o assunto.

Dentro dessa abordagem, tem-se como objetivo geral analisar como ocorre e qual é a importância da perícia em um processo judicial de propriedade intelectual, averiguando quais são os conhecimentos necessários e como deve ser a atuação processual do perito. Para isso, denota-se um levantamento de informações teóricas, bem como de situações práticas, nas quais podem ser verificados trabalhos assertivos em algumas e episódios que ocasionaram a anulação da prova pericial em outras.

\subsection{A Prova Pericial}

A perícia judicial subsidia o magistrado em determinada área na qual ele não possua conhecimentos específicos sobre o assunto, auxiliando-o no embasamento de sua decisão. Em determinadas situações, é fundamental para pautar, esclarecer, direcionar e elucidar o juiz e as partes do processo.

Para Avelino (2016), essa modalidade de prova encontra fundamento na necessidade de conhecimento técnico, científico ou especializado, de qualquer ordem, para a verificação de fato ou objeto de prova no processo. Nesse contexto, é imprescindível a aplicação do princípio do contraditório, devendo ser dado aos interessados o direito de argumentação e de defesa após a produção da prova pericial, de modo a garantir o direito de resposta voltado para a solução justa do litígio e a tutela das posições jurídicas subjetivas das partes.

O Código de Processo Civil (CPC) tipifica a prova pericial em três modalidades: exame, vistoria e avaliação. De acordo com Alberto Filho (2008) e Marques (1997), o exame é a inspeção realizada pelo perito para cientificar-se da existência de fato ou circunstância incidindo sobre pessoas ou coisas, tratando-se de bens móveis, semoventes, livros, documentos e pessoas; a vistoria, de maneira análoga, diz respeito a bens imóveis; finalmente, a avaliação trata de estimar o valor de mercado de um bem em lide.

$\mathrm{O}$ referido $\mathrm{CPC}$ elenca ainda as etapas relacionadas à produção da prova pericial, sendo que o expert deve pautar seu trabalho dentro dos limites e exigências da lei processual de modo a conduzir a produção da prova de maneira apropriada.

O magistrado, segundo critérios legais, é soberanamente livre quanto à indagação da verdade e da apreciação de provas com o fim de fundamentar sua decisão, nos casos em que este não concordar, apresentar dúvidas a respeito das conclusões, ou avaliar o laudo pericial como 
superficial, ou de credibilidade duvidosa, ele pode determinar outra perícia (DIDIER JUNIOR; BRAGA; OLIVEIRA, 2015).

Conforme apontam Marinoni e Arenhart (2015), a segunda perícia ocorre quando o juiz não está convencido com a perícia inicial, seja pelo fato de não ter sido esclarecedora ou porque o perito se revelou não confiável. Pode ser requerida pelas partes ou pelo Ministério Público, sendo complementar ou substitutiva. Independentemente de solicitação das partes, o próprio magistrado também pode determiná-la ex officio, se entender necessário.

\subsection{O Perito Judicial}

Uma definição para esse profissional é dada da seguinte maneira: "O perito é especialista em determinado campo do saber, que atua como auxiliar eventual do juízo, protagonizando a prova pericial" (DIDIER JUNIOR; BRAGA; OLIVEIRA, 2015, p. 264).

O perito será nomeado pelo magistrado, sendo escolhido entre os profissionais aptos, fazendo-se necessário ter habilitação em cadastros mantidos pelo tribunal ao qual o juiz está vinculado (BRASIL, 2015).

Sabendo o papel a ser desempenhado, é preciso elucidar as condições para o encargo. Segundo Martins (2008), três requisitos básicos devem ser utilizados para a escolha de um perito: (i) a sua nomeação depende de inscrição em livro próprio, estando a inscrição sujeita ao preenchimento de determinadas condições, podendo-se conceber como variação desse sistema a previsão legal de que determinadas espécies de perícia deverão ser realizadas por peritos oficiais; (ii) a nomeação depende, em regra, da detenção de título oficial na ciência ou arte exigida para a execução da perícia; e (iii) a nomeação é livre, isto é, não existem critérios rigidamente definidos para nortear a escolha do perito pelo juiz.

A lei brasileira prevê a nomeação de mais de um perito, podendo a parte indicar mais de um assistente técnico em casos de perícia complexa (BRASIL, 2015), ou seja, se a perícia envolver conhecimentos em mais de uma área de atuação e esta não for dominada pelo primeiro perito.

Além do perito judicial, é importante destacar a atuação do assistente técnico, figura intrinsecamente parcial, funcionando como olhos, boca e ouvidos da parte, fiscalizando e cooperando com o perito na produção da prova técnica e científica (AVELINO, 2016). Enquanto cabe ao perito a elaboração do laudo pericial de forma imparcial e sem julgamento, ao assistente técnico cabe a elaboração de parecer técnico baseado na concordância ou não referente aos apontamentos do laudo. Os assistentes técnicos normalmente também são os responsáveis pela elaboração de quesitos a serem respondidos pelo perito no laudo pericial.

Para Aguillar (2016), em causas envolvendo propriedade intelectual, não bastará ao perito o conhecimento técnico meramente acadêmico acerca da matéria que constitui o objeto do processo, deve o profissional conjugar o conhecimento científico com o profissional, pois a ninguém é dado ser expert sem possuir experiência. Tal observação se aplica sobretudo no campo das patentes, em que o profissional que seja unicamente um teórico, não tendo jamais tido a experiência prática, quotidiana, de implementar novos processos ou produtos em unidades industriais, certamente que não se torna o técnico no assunto exigido pela lei.

Para Rocha (2013), em ações envolvendo direitos de natureza de propriedade industrial, em especial aqueles decorrentes de patentes, a dificuldade não reside na produção da prova 
pericial, mas sim em encontrar peritos que detenham suficiente conhecimento e especialidade comprovada na matéria a que são levados a opinar.

No tocante à ética, é imperioso ao perito obedecer aos princípios e valores norteadores de tal ordem. Para Alves (2011), a ética do perito é indispensável para sua boa atuação e esse profissional deve considerar os efeitos de seu trabalho voltados para o benefício da sociedade propiciando o bem-estar de todos que têm interesse no deslinde da controvérsia.

Há punição ao perito, caso haja comprovação de má fé, prevista em lei:

O perito que, por dolo ou culpa, prestar informações inverídicas responderá pelos prejuízos que causar à parte e ficará inabilitado para atuar em outras perícias no prazo de 2 (dois) a 5 (cinco) anos, independentemente das demais sanções previstas em lei, devendo o juiz comunicar o fato ao respectivo órgão de classe para adoção das medidas que entender. (BRASIL, 2015)

O perito deve ainda compreender que o profissionalismo, a ética e o respeito aos envolvidos trazem reconhecimento de forma a engrandecer seu prestígio e sua reputação.

\subsection{O Laudo Pericial}

O laudo é a materialização da prova pericial, o instrumento pelo qual o perito reporta seu trabalho contendo suas observações, pesquisas, respostas aos quesitos elaborados pelas partes e pelo magistrado, suas conclusões, práticas realizadas e a metodologia utilizada.

Para a doutrina, é considerada uma "[...] exposição minuciosa, circunstanciada, fundamentada e ordenada das apreciações e interpretações realizadas pelo perito, com a pormenorizada enumeração e caracterização dos elementos contábeis manuseados e examinados" (ZARZUELA; THOMAZ; MATUNAGA, 2000, p. 86).

Ao juiz e às partes, é facultada a elaboração de quesitos, os quais o perito deverá responder de forma clara e objetiva no laudo pericial, sendo esse documento composto estruturalmente de uma etapa expositiva e uma etapa conclusiva (ALMEIDA; OLIVEIRA; PANNO, 2000).

Conforme prevê o artigo 473 do Código de Processo Civil, o laudo deve, obrigatoriamente, conter os seguintes requisitos:

O laudo pericial deverá conter:

I - a exposição do objeto da perícia;

II - a análise técnica ou científica realizada pelo perito;

III - a indicação do método utilizado, esclarecendo-o e demonstrando ser predominantemente aceito pelos especialistas da área do conhecimento da qual se originou;

IV - resposta conclusiva a todos os quesitos apresentados pelo juiz, pelas partes e pelo órgão do Ministério Público.

$\S 1 .^{\circ}$ No laudo, o perito deve apresentar sua fundamentação em linguagem simples e com coerência lógica, indicando como alcançou suas conclusões.

$\S 2 .^{\circ}$ É vedado ao perito ultrapassar os limites de sua designação, bem como emitir opiniões pessoais que excedam o exame técnico ou científico do objeto da perícia. 
§3. ${ }^{\circ}$ Para o desempenho de sua função, o perito e os assistentes técnicos podem valer-se de todos os meios necessários, ouvindo testemunhas, obtendo informações, solicitando documentos que estejam em poder da parte, de terceiros ou em repartições públicas, bem como instruir o laudo com planilhas, mapas, plantas, desenhos, fotografias ou outros elementos necessários ao esclarecimento do objeto da perícia. (BRASIL, 2015, art. 473)

Para Oliveira e Oliveira (2017), o trabalho pericial precisa ser planejado e organizado, o perito deve se atentar a responder aos quesitos de forma objetiva, furtando-se às costumeiras provocações no sentido de influenciar a resposta, já que os quesitos dúbios, na maior parte das vezes, apenas servem para dificultar o trabalho pericial.

Conforme prevê o artigo 470 do Código de Processo Civil, apenas o juiz pode indeferir quesitos, mas o perito pode se negar a responder àqueles que não entender pertinentes, para isso, deve solicitar anuência do magistrado, por meio de solicitação formal anteriormente ao início de suas atividades, ou ainda deixando-os sem resposta no laudo pericial, para posterior aprovação do julgador.

Para Bustamante (1996), o laudo terá credibilidade em decorrência da justificativa das respostas e não das opiniões subjetivas do perito, sendo assim, deve estar focado em respostas objetivas, assertivas e respaldadas por estudos em conformidade com a prática legal existente, sem emitir juízo de valor.

De acordo com Avelino (2016), é essencial haver uma fundamentação do laudo pericial, ou seja, este não pode vir somente acompanhado das respostas aos quesitos das partes e do juiz. $\mathrm{O}$ perito deve expor o objeto da perícia, relatar analiticamente a atividade realizada e indicar o método escolhido para o exame.

No que tange à forma e ao conteúdo, há que se destacar que o perito deve empregar linguagem simples e com coerência lógica, indicando como alcançou suas conclusões, isso significa se ater a elucidar os fatos de maneira clara, simples e direta. Para isso, pode valer-se de leis, doutrinas, manuais técnicos, experiência prática e até mesmo usar jurisprudências para respaldar suas alegações.

O laudo pericial é um documento auxiliar no processo, isso significa que o magistrado tem liberdade para considerá-lo (ou não) em seu julgamento. Se o magistrado entender que não houve respeito ao Código de Processo Civil, seja em qualquer um dos seus artigos, pode anular a prova pericial, tanto por iniciativa própria ou a pedido das partes. Variadas situações podem levar a isso, como parcialidade do perito, respostas sem fundamentação, conclusões equivocadas ou sem justificativa, metodologia não indicada ou não condizente, entre outras.

Um laudo bem redigido é decisivo para o esclarecimento técnico de um processo e pode ser fundamental para balizar a sentença. Entretanto, se o laudo estiver inconsistente, pode trazer consequências indesejáveis, dúvidas, incertezas, até mesmo culminando com a anulação da prova pericial. 


\section{Metodologia}

Conforme ressalta Gil (2008), esta pesquisa tem caráter exploratório, com a principal finalidade de desenvolver e de esclarecer conceitos, tendo em vista a formulação de problemas mais precisos ou hipóteses pesquisáveis para estudos posteriores, sendo realizada na forma de pesquisa bibliográfica e documental. Tem abordagem qualitativa e, quanto à natureza do objeto, é uma pesquisa básica, ou seja, que objetiva gerar novos conhecimentos, úteis para o avanço da ciência.

A revisão bibliográfica foi realizada por meio da coleta de dados secundários, utilizando artigos científicos disponíveis nas bases de dados Scielo, Google Acadêmico e Web of Science, bem como pela consulta a livros, doutrinas e legislações sobre propriedade intelectual e prova pericial.

Além disso, foram pesquisados julgados de forma a trazer alguns casos, objeto de litígio no campo da propriedade intelectual. Cada um deles foi investigado em sua integralidade, desde a primeira instância até as instâncias superiores, nos tribunais correspondentes. As palavras-chave utilizadas na pesquisa, de maneira isolada ou agrupada, foram: propriedade industrial, direitos autorais, perícia, substituição, perito, segunda perícia, laudo, laudo inconclusivo.

A escolha dos julgados aqui citados baseou-se na "Metodologia de Análise de Decisões (MAD)" proposta por Roberto Freitas Filho e Thalita Moraes Lima (2010), a qual propõe uma forma metodológica de produção de trabalhos teóricos no campo do Direito.

\section{Resultados e Discussão}

A presente seção apresenta quatro casos de litígios em propriedade intelectual, selecionados de acordo com a representatividade de situações positivas e negativas envolvidas na produção da prova pericial. Todos se referem a decisões questionadas em instâncias superiores.

Os dois primeiros contêm abordagens que elencam alguns dos procedimentos periciais, destacando o trabalho assertivo do perito, o peso da prova pericial perante cada sentença e sua importância para o esclarecimento dos fatos.

Os dois últimos retratam situações nas quais ocorreu a anulação da primeira prova pericial, seja por insuficiência técnica, equívocos do perito, laudo pericial mal elaborado, ou outras razões que eventualmente não atenderam à demanda, conforme determina o CPC.

\subsection{Caso I - Desenho Industrial}

Trata-se de uma disputa envolvendo desenho industrial, na qual duas conhecidas empresas de bebida entraram em litígio devido à similaridade de embalagens.

A parte autora, "Empresa de Águas Ouro Fino Ltda.", ajuizou a ação por razão de uma suposta imitação da embalagem de água mineral utilizada em seus produtos "Ouro Fino Mini Blue" e "Ouro Fino Mini Red", conforme registro de desenho industrial número DI6403527-1, protocolado em $1^{\circ}$ de outubro de 2004, sob o título "Configuração Aplicada em Garrafão".

A empresa ré, "Coca-Cola Indústrias Ltda.", foi acusada de se apropriar da configuração tridimensional ora protegida. O produto envolvido, "Coca Cola Copabola" também possuía 
registro de desenho industrial de número DI6504084-8, depositado em 8 de novembro de 2005 sob título "Configuração Ornamental Aplicada em Garrafa".

A ação teve início em 19 de maio de 2006 junto ao Tribunal de Justiça do Estado do Paraná, na $16^{\circ}$ Vara Cível do Foro Central da Comarca da Região Metropolitana de Curitiba, encerrando em 11 de setembro de 2018.

RECURSO DE APELAÇÃO CÍVEL - AÇÃO INDENIZATÓRIA - DESENHO INDUSTRIAL-PROPRIEDADE INTELECTUAL-PLEITO JULGADO IMPROCEDENTE - INSURGÊNCIA DOS AUTORES - ALEGAÇÃO DE PLÁGIO DE EMBALAGEM INOCORRENCIA - MERA SEMELHANÇA QUE NÃO CARACTERIZA PLÁGIO OU OFENSA A LEI 9.279/96 - REGISTRO PERANTE O INPI - REGULARIDADE A SIMPLES SIMILARIDADE DOS PRODUTOS NÃO SE CONFIGURA DE PRONTO EM CONTRAFAÇÃO - PERÍCIA TÉCNICA CONCLUSIVA - ÔNUS DOS AUTORES - ARTIGO 333, I DO CPC - DEVER DE INDENIZAR NÃO CONFIGURADO INAPLICABILIDADE DOS ARTIGOS 186 E 927 DO CÓDIGO CIVIL - SENTENÇA MANTIDA - RECURSO NÃO PROVIDO. (TJPR, 2016)

Enquanto a autora alegava a infração de seu desenho industrial, que contemplava uma embalagem com formas arredondadas, a ré entendia que a ação era improcedente alegando distinção tanto entre as embalagens quanto entre os registros de desenho industrial.

Após tentativa frustrada de acordo, o juiz saneou o processo e deferiu a produção de prova pericial. Um primeiro perito foi nomeado, mas recusado pelas partes em função da discordância sobre o valor dos honorários, então, um segundo profissional foi selecionado e aceito, dando início ao trabalho.

Pautado pela Lei n. 9.279/96 e normativos específicos do Instituto Nacional da Propriedade Industrial (INPI), o perito, ao empregar técnicas de inspeção visual, conseguiu avaliar corretamente o caso, utilizando-se de comparações e de análises particulares dos objetos, confrontando-os aos respectivos registros de desenho industrial.

$\mathrm{O}$ perito concluiu que as embalagens eram distintas e não se tratava de contrafação, conforme trechos do laudo pericial, citados na sentença de segunda instância, reproduzida parcialmente, a seguir.

A respeito, vejamos o que dispõe trechos da perícia técnica judicial a respeito das embalagens, a qual se encontra encartada as fls. 528/564: Fls. 545: verifica-se que ambas apresentam a mesma forma geométrica, entretanto há diferenças dimensionais, de cores e de adesivos de logomarca "Colocando-se as garrafas lado a lado e as observando de cima para baixo, pode-se afirmar que, sob este ângulo, as garrafas não são semelhantes" Fls. 546: "é reduzida a possibilidade de os consumidores confundirem a origem das garrafas e consequentemente dos produtos" Fls. 557: "os elementos distintivos efetivamente diferenciam a garrafa protegida através do desenho industrial DI6403527-1 da embalagem protegida através do registro industrial DI6504084-8 sob o ponto de vista de design e conceitual" E por fim, o parecer de fls. 558: "pelas análises efetuadas, o objeto protegido pelo DI6403527-1 não representa imitação servil ou Ora, vejamos que o laudo pericial é bastante claro, abrangendo análise técnica e também sob o ponto de vista comercial perante os consumidores, demonstrando que não há semelhanças suficientes a confundir o consumidor ou a violar a propriedade industrial registrada por primeiro. Desta forma, vejamos que não há ato ilícito praticado pela 
Apelada para que haja condenação à reparação, na forma do que dispõe os artigos 186 e 927 do Código Civil. Assim, ainda que a Apelante tenha realizado Certificado de Registro junto ao INPI antes da Apelada nos termos do artigo 7. ${ }^{\circ}$ da Lei 9.279/96, se tratam de produtos com características distintas e não idênticas como quer fazer crer a Apelante, não havendo que se falar no presente caso, em violação da propriedade industrial. (TJPR, 2016)

Segundo o laudo pericial, que abrangeu análise técnica e também avaliação sob a ótica comercial, ficou demonstrado que não havia semelhanças suficientes para confundir o consumidor ou violar a propriedade industrial registrada por primeiro. Em que pese o fato de as dimensões e de a capacidade volumétrica de ambas as embalagens serem similares, a perícia foi categórica em descartar colidência entre a embalagem da ré e o desenho industrial da autora.

A ação foi julgada improcedente com decisão mantida em segunda instância. A autora ainda recorreu perante os tribunais superiores STJ e STF, mas sem êxito, pois, em tais instâncias superiores, não foi possível rever as provas. Assim, o processo transitou em julgado e, posteriormente, foi arquivado.

O laudo pericial foi mencionado em ambas as sentenças, sendo objeto importante na caracterização dessas decisões. Isso denota sua assertividade quanto aos esclarecimentos necessários $e$ às razões das conclusões.

Quanto ao trabalho do expert, o caso estudado apontou que processos dessa natureza requerem técnicas comparativas próprias de análise e, não obstante, necessitam, de maneira primordial, da demonstração dos resultados por meio de elementos específicos como quadros e comparativos de imagens, os quais, certamente, devem ser de conhecimento de um perito conceituado na área.

\subsection{Caso II - Direitos Autorais (Música)}

Trata-se de uma disputa envolvendo direitos autorais. O litígio ocorreu devido à veiculação, sem autorização, de um trecho de uma música em comercial publicitário de televisão.

A autora, "Warner Chappell Edições Musicais Ltda.", ajuizou ação contra as rés, "Unilever Brasil Alimentos Ltda." e "Ogilvy \& Mather Brasil Comunicação Ltda.", após tomar conhecimento de que a música "Pra sempre na minha vida" estaria sendo utilizada na campanha publicitária da marca da maionese Hellmann's, produto fabricado pela primeira ré.

Um segundo processo movido pelos autores da música, Luis Cláudio Paulino de Almeida e Wagner Dias Bastos, tramitou em apenso contra as mesmas rés. A ação teve início em 25 de novembro de 2009 junto ao Tribunal de Justiça do Estado de São Paulo, na 27ª Vara Cível do Foro Central Cível da Comarca de São Paulo, encerrando-se em 5 de dezembro de 2009.

AGRAVO EM RECURSO ESPECIAL N. 1.161.233 - SP (2017/0216648-9) RELATOR: MINISTRO MARCO AURÉLIO BELLIZZE AGRAVANTE: OGILVY E MATHER BRASIL COMUNICAÇÃO LTDA ADVOGADOS: MARIA CRISTINA CORRÊA DE CARVALHO JUNQUEIRA - SP113041 DANILO ORENGA CONCEIÇÃO SP315244 LUIZ FERNANDO BLUMENAL PARDELL - SP357323 AGRAVADO: WARNER/CHAPPELL EDICOES MUSICAIS LTDA ADVOGADOS: MARIA LUIZA DE FREITAS VALLE EGEA - SP035225 MARIA ELIANE RISE JUNDI - SP046088 
AGRAVO EM RECURSO ESPECIAL. AÇÃO DE COBRANÇA. INDENIZAÇÃO POR DANOS MORAIS. REPRODUÇÃO DE TRECHO DE MÚSICA SEM AUTORIZAÇÃO. EXISTÊNCIA DE CONTRAFAÇÃO. DANO MORAL DOS AUTORES PRESUMIDO. REEXAME FÁTICO-PROBATÓRIO DOS AUTOS. INCIDÊNCIA DA SÚMULA 7/STJ. AGRAVO CONHECIDO PARA NEGAR PROVIMENTO AO RECURSO ESPECIAL. DECISÃO. (STJ, 2017)

Inicialmente, houve tentativa de solução extrajudicial, infrutífera, uma vez que a parte autora alegava que não havia concedido autorização de uso e que não havia acordo comercial para veiculação da música, enquanto a ré afirmava que se tratava de música distinta, além de ser veiculada apenas em uma breve etapa dentro do comercial.

A tramitação judicial do caso foi longa, sendo que cada parte apresentou parecer técnico, ambos antagônicos e elaborados por músicos experientes, motivo pelo qual a prova pericial tornou-se ainda mais importante.

As partes solicitaram prova pericial, documental e testemunhal. Uma perita em direitos autorais foi nomeada, entretanto, ela solicitou uma segunda nomeação, de um profissional versado em música, para a auxiliá-la na demanda.

Ciente de que a perita nomeada não tinha formação musical, mas era bem entendida acerca da matéria de direitos autorais, o juiz determinou que ela indicasse pessoa de sua confiança com notória capacidade técnica (maestro, musicista, professor, pesquisador, etc.) a fim de auxiliá-la nos trabalhos periciais.

Uma vez cumpridas as etapas processuais obrigatórias, a perícia foi realizada e concluiu que houve reprodução da melodia original, incluindo divisão rítmica, gênero musical e parte da letra, constatando ainda que, do ponto de vista melódico, os trechos eram praticamente iguais e facilmente identificáveis por uma pessoa leiga.

Embora as rés alegassem que a inserção de apenas um trecho, por cinco segundos, em um comercial que possuía duração total de 30, não seria motivo suficiente para caracterizar indenização, se verificou no laudo pericial que esses cinco segundos eram justamente relacionados ao refrão e estavam inseridos no final do anúncio, tal qual uma assinatura na peça publicitária, provocando no telespectador uma associação entre a música e o produto divulgado.

Vários trechos do laudo foram citados na sentença de primeira instância, a qual determinou procedentes os pedidos da autora, condenando as rés ao pagamento de danos materiais, a serem apurados em fase de liquidação de sentença, e de danos morais aos autores da obra musical.

A Unilever interpôs Recurso Especial, que teve seu seguimento negado pelo TJSP. Foi também interposto Agravo de Instrumento igualmente negado.

Tendo a decisão transitado em julgado, iniciou-se a fase de cumprimento de sentença para apuração da indenização pelo dano material. A mesma perita foi designada para cálculo de valores, pois foi necessário fazer um levantamento dos preços praticados no mercado musical publicitário e realizar estimativas financeiras pertinentes ao escopo do caso. No curso do cumprimento da sentença, as partes compuseram acordo, baseadas nos preços levantados na perícia.

Ao proceder o estudo desse caso, comprova-se que a prova pericial foi fundamental para dirimir a questão, uma vez que as partes apresentaram elementos processuais em forma de pareceres técnicos encorpados, porém contrários. Sendo a matéria muito particular, necessitou-se de especialista, que acabou concluindo pela infração aos direitos autorais. 
Esse tipo de análise e conclusão, além de não ser trivial, demandou práticas interdisciplinares por meio de avaliações específicas em âmbito musical, contemplando técnicas relacionadas à harmonia, à melodia e à letra, além da expertise na interpretação da Lei dos Direitos Autorais.

Levando em consideração todos os elementos desse caso, verifica-se que algumas produções periciais no campo dos direitos autorais podem ser tão (ou mais) complexas quanto as da área de propriedade industrial, devido ao fato de envolverem expressões artísticas peculiares.

Para resposta a quesitos relacionados a talento e à criatividade, não bastam somente conhecimentos relativos à propriedade intelectual, às leis e doutrinas, mas também a expertise artística relacionada ao objeto do litígio.

$\mathrm{O}$ perito em direitos autorais pode ser considerado o agente que proporciona o esclarecimento imparcial, favorecendo a análise do magistrado, pois este nem sempre reúne os atributos artísticos, literários ou científicos suficientes para ter assertividade em suas decisões em matérias particulares.

\subsection{Caso III - Software}

Trata-se de uma ação envolvendo programa de computador. O litígio ocorreu em função de alegação de infração relativa a um sistema de automação empresarial, no qual houve a utilização do mesmo código fonte.

A demanda foi proposta após uma parceria comercial não concretizada, na qual um ex-funcionário da autora desenvolveu sistema similar, a pedido da ré, que passou a comercializar o produto sem anuência do desenvolvedor.

A autora, "Memoconta Engenharia", ajuizou ação de indenização por dano material e moral contra a ré, "Bematech Indústria e Comércio de Equipamentos Eletrônicos Ltda.", alegando contrafação de software, particularmente, um programa denominado "MicroCash".

A ação teve início em 4 de fevereiro de 2005 junto ao Tribunal de Justiça do Estado de São Paulo, na 21 a Vara Cível do Foro Central Cível da Comarca de São Paulo e encontra-se ainda em andamento na presente data.

RECURSO ESPECIAL. AGRAVO DE INSTRUMENTO NA ORIGEM. PROPRIEDADE INDUSTRIAL. ALEGADA CONTRAFAÇÃO. PROVA PERICIAL DETERMINADA. PERITO NOMEADO. CONHECIMENTO TÉCNICO CORRELATO. AUSÊNCIA. SUBSTITUIÇÃO DE PERITO NOMEADO. NECESSIDADE. RECURSO ESPECIAL PROVIDO. (STJ, 2018)

Após apresentação de petição inicial e citação da parte ré, esta se manifestou por meio de contestação apresentando laudo técnico de engenheiro especializado na área, alegando tratar-se de sistema distinto, somado ao fato de ser similar a diversos outros existentes no mercado, afirmando que a autora não possuía patente concedida, nem registro de software, junto ao INPI.

Em primeira instância, o magistrado definiu que não seriam necessárias outras provas além daquelas constantes nos autos e proferiu sentença favorável à autora.

A parte requerente interpôs recurso buscando majorar o valor da indenização por entender que este não era condizente com o proposto na petição inicial. Já a parte requerida recorreu por não estar de acordo com a perda da causa. 
O processo regressou para uma nova fase de produção de provas, na qual uma perita em propriedade intelectual foi nomeada. Ocorreram duas etapas de produção de prova pericial, sendo ambas anuladas em instância superior.

Algumas situações particulares sucederam durante as perícias. Em uma delas, a ré alegou que não comercializava mais o equipamento que embarcava o software, então a perita solicitou a fabricação exclusiva de um novo produto, algo que não ocorreu. Assim, o laudo pericial foi produzido conforme informações já existentes nos autos, somadas a uma vistoria em um protótipo feito pela parte autora.

Outro ponto controverso foi o fato de a perita ter se valido de auxiliares com conhecimento em informática para realizar a perícia, os quais foram escolhidos por conta própria, sem terem sido nomeados pelo magistrado e oficialmente reconhecidos no processo.

Após produção da prova pericial, a ré alegou falta de conhecimento técnico da perita e parcialidade, além do fato de ter realizado perícia em produto distinto do sistema que efetivamente incorporava o software. Assim solicitou nova perícia, sem sucesso. Novamente houve sentença favorável à autora, dessa vez, baseada no laudo pericial, reproduzindo todas as suas conclusões.

A ré, insatisfeita com a decisão, interpôs Recurso Especial, cujo seguimento foi negado pelo Tribunal de Justiça de São Paulo. Com o intuito de que o Recurso Especial pudesse ser apreciado pelo STJ, interpôs Agravo de Instrumento e, enfim, nessa ocasião, o STJ determinou nulidade da perícia.

Tal decisão enfatizou que assistia razão à Bematech, pois ficou evidenciado que o perito deveria reunir o conhecimento técnico adequado para realizar a perícia sem precisar se valer de auxiliares. Diante de tal quadro, foi determinada a substituição da perita e nova produção de prova pericial.

O processo continua em tramitação até o momento, mas o fato de a empresa ré alegar que não possui mais nenhum equipamento, ou sequer documentos relativos ao projeto e concepção do produto inicial, torna a prova pericial extremamente complexa. O próprio magistrado autorizou o novo perito a definir a melhor maneira de produzir a prova, ainda não iniciada.

Com relação aos eventos verificados no decorrer da produção da prova pericial anulada, essa prova mostrou-se equivocada em alguns pontos.

Primeiramente, verifica-se que não houve atendimento ao artigo 466, parágrafo $2^{\circ}$, do $\mathrm{CPC}$, não comunicando corretamente as partes e os assistentes técnicos para acompanhamento de algumas diligências realizadas.

Depois, outro fato relevante foi a solicitação, por parte da perita, da atuação conjunta de outros profissionais técnicos, sem a autorização e nomeação pelo magistrado, contrariando o artigo 475 do CPC, que confere apenas ao juiz a nomeação de múltiplos peritos ou de uma equipe multidisciplinar, uma vez que todos os peritos envolvidos na realização de perícias complexas devem atender aos mesmos deveres e se sujeitarem às mesmas responsabilidades.

Mesmo havendo boa-fé por parte da perita, a ausência de conhecimento específico, somado a uma sucessão de eventos processuais indesejados, fragilizou a prova pericial, culminando com sua nulidade.

O caso demonstra que o conhecimento técnico-científico é essencial ao expert, que deve atentar-se aos deveres e responsabilidades legalmente estabelecidos. Apenas o conhecimento jurídico no âmbito da propriedade intelectual não assegura meio suficiente para apuração técnica em relação a equipamentos complexos, como em casos dessa natureza. 


\subsection{Caso IV - Patente}

Trata-se de uma ação envolvendo um pedido de patente intitulado "Sistema Estrutural para Construções Metálicas", depositado junto ao INPI sob número PI0504031-0, em 19 de setembro de 2005.

O autor, "Samuel Souto", ajuizou ação por infração de propriedade industrial contra a ré, "Kloeckner Metais Brasil S/A", por comercializar um sistema estrutural destinado a construções metálicas com perfis específicos.

O litígio originou-se após o autor ter firmado um acordo com um consórcio de empresas, entre elas a ré, para exploração da suposta invenção, no qual os valores devidos não foram devidamente pagos.

A ação teve início em 20 de fevereiro de 2009 junto ao Tribunal de Justiça do Estado do Paraná, na Primeira Vara Cível de Ponta Grossa e encontra-se ainda em andamento na presente data.

AGRAVO DE INSTRUMENTO. AÇÃO COMINATÓRIA. PROPRIEDADE INDUSTRIAL. DEFERIDA PROVA PERICIAL PARA VERIFICAÇÃO DE ALEGADO USO INDEVIDO DE PATENTE. COMUNICAÇÃO DOS ATOS. AUSÊNCIA DE ATENDIMENTO AO CONTIDO NO ART. 431, A, DO CÓDIGO DE PROCESSO CIVIL. ENVIO DE CORREIO ELETRÔNICO PELO PERITO ÀS PARTES COM CURTA ANTECEDÊNCIA À DATA DA EFETIVAÇÃO DA PERÍCIA EM OUTRA CIDADE. IMPOSSIBILIDADE DE PARTICIPAÇÃO. NECESSIDADE DE REALIZAÇÃO DE NOVA PERÍCIA. RECURSO CONHECIDO E PROVIDO. (TJPR, 2015)

Em fase de saneamento do processo, as partes apresentaram suas razões, entre estas, o autor alegou quebra de contrato e infração de sua propriedade intelectual, e a ré justificou que já utilizava sistemas similares, informando que o pedido de patente do autor ainda não havia sido concedido.

Foi determinada a produção da prova pericial, uma vez que havia necessidade de averiguação técnica do sistema, comparação com o escopo de proteção patentário (reivindicações) e constatação (ou não) de infração.

Para esse caso, foram indicados três peritos. Uma primeira expert foi refutada em decorrência de impugnação dos honorários propostos, o segundo profissional declinou por não apresentar condições técnicas para atuar no caso e, finalmente, o terceiro aceitou o encargo.

No decorrer do seu trabalho, o perito deveria, por obrigação legal, informar sobre a realização da perícia, com antecedência (razoável) e que esta seria realizada em obras nas cidades de Cascavel e Ponta Grossa. No entanto, o perito determinou a data para a diligência na primeira cidade com apenas 48 horas de antecedência, quando seria necessário um deslocamento de mais de $400 \mathrm{~km}$ por parte dos assistentes técnicos, inviabilizando sua participação.

Quanto à vistoria em Ponta Grossa, o perito não confirmou o horário exato, afirmando que "poderia acontecer por volta das 11 horas", novamente dificultando um entendimento para que as partes acompanhassem os trabalhos periciais.

Tais atitudes denotam a importância da comunicação processual objetiva entre os envolvidos, pois a condução das vistorias sem haver a presença das partes, na figura de seus assistentes técnicos, viola o princípio do contraditório e da ampla defesa. 
Outro ponto controverso foi a alegação de que haveria certa aproximação entre o perito e um dos assistentes técnicos. Tal afirmação trouxe dúvidas quanto ao compromisso ético do profissional, que deveria prezar pela imparcialidade e neutralidade.

Em instância superior, o Tribunal de Justiça do Estado do Paraná decidiu pela nulidade da perícia justificando a decisão baseada na premissa na qual a determinação de início dos trabalhos periciais sendo realizada com curta antecedência, igualou-se à ausência integral de comunicação, evidenciado o desacerto da decisão de primeiro grau que não reconheceu a justificativa como plausível.

Por essa razão, nova perícia foi realizada pelo mesmo profissional, dessa vez, segundo critérios legalmente corretos quanto aos procedimentos. Houve ainda uma ação cautelar incidental para busca e apreensão de produtos a serem periciados em novas localidades e inclusão de outras empresas em polo passivo.

Novo laudo pericial foi produzido, sendo este aceito pelo magistrado. Houve concordância das partes rés, enquanto a parte autora contra-argumentou e solicitou complementação pericial, indeferida pelo juiz.

A nova perícia realizada em três obras, em cidades distintas, avaliou em detalhes o perfil metálico dos produtos e foi conclusiva em relação ao fato de não haver identidade entre eles, embora fossem similares, descrevendo suas características técnicas e apontando as diferenças existentes.

As conclusões foram as seguintes:

O tipo de perfil possui ampla utilização;

O produto produzido pelo Autor não apresenta qualquer diferenciação dos demais existentes no mercado há anos;

O Descritivo do Sistema não forneceu proporções de medidas para permitir a diferenciação entre o produto desenvolvido pelo Autor e outros existentes;

Ao realizar a medição das terças instaladas na Loja Balaroti, foram identificadas angulações diferentes em cada uma das partes inclinadas do enrijecimento trapezoidal da alma, o que permitiu concluir que não se trata de reprodução do produto produzido pelo Autor;

O perfil projetado no projeto da Klabin é o mesmo utilizado na Loja Balaroti;

Embora houvesse "semelhança bastante grande" entre os produtos vistoriados na obra em Cascavel e o produto desenvolvido pelo Autor, o Descritivo do Sistema não apresentava medidas que permitissem a realização de exame de proporcionalidade. (TJPR, 2019)

Em termos técnicos, a prova pericial se mostrou clara e elucidativa em relação aos aspectos construtivos do sistema objeto da lide, contribuindo positivamente para o esclarecimento dos fatos e o entendimento do julgador.

Paralelamente à ação judicial, tramitando na esfera administrativa, o pedido de patente, após passar pelo exame técnico, foi indeferido pelo INPI por não satisfazer a requisitos de novidade e de atividade inventiva.

Em sua sentença, baseada no laudo pericial e na ausência de concessão do pedido pelo INPI, o magistrado declarou a ação improcedente e determinou que o requerente arcasse com 
os custos processuais, o qual recorreu da decisão, estando a ação, atualmente, em tramitação em instância superior.

Mesmo o perito sendo bem-sucedido do ponto de vista do esclarecimento técnico da matéria, esse caso demonstra algumas situações que devem ser cuidadosamente observadas e evitadas: (i) a comunicação deficitária do perito com as partes e incertezas quanto às datas e horários; (ii) a realização de vistorias sem a presença dos assistentes técnicos; (iii) a falta de atenção aos procedimentos ordinários processuais; e (iv) o comportamento passível de questionamento pelas partes quanto à parcialidade ou omissão de informações.

Ética, organização e coerência quanto ao cumprimento do encargo, associados à cordialidade e objetividade durante uma diligência, devem ser também levados em consideração pelo profissional para direcionar o trabalho pericial.

\section{Considerações Finais}

Percorreu-se um caminho para desvendar questões sobre a produção da prova pericial em processos de propriedade intelectual, aliando elementos práticos e teóricos no sentido de esclarecer sua função e expor sua execução, trazendo uma noção do perfil profissional recomendado para atuação em demandas dessa natureza.

Em sendo a prova pericial um dos possíveis meios de esclarecimento processual, é considerada em algumas circunstâncias como essencial na elucidação da lide, principalmente em ações que envolvem conhecimentos específicos como em caso de interpretação de patente de equipamento complexo ou mesmo em avaliação de infração de direitos autorais de obras artísticas.

O trabalho de produção da prova pericial deve ser realizado por profissional capacitado, de confiança do juiz, e que possua conhecimentos técnicos apropriados ao objeto da ação, sendo primordial o fato de ser versado em propriedade intelectual.

Nessa seara, deve-se ressaltar que o expert não é um profissional necessariamente com formação jurídica, assim, ele deve observar atentamente o desenvolvimento do seu trabalho sob a ótica do Direito, de maneira a respeitar a legislação, tanto no ponto de vista da análise técnica quanto comportamental. Nesse sentido, o encargo deve ser pautado pelo que determina o Código de Processo Civil, principalmente no tocante às diretrizes da produção da prova pericial e das atribuições do perito.

De acordo com os casos estudados, os trabalhos periciais bem conduzidos resultam em reconhecimento pelo magistrado, provendo celeridade e esclarecimento. Em contrapartida, equívocos dos mais variados tipos podem acarretar na nulidade da perícia, exigindo sua substituição.

\section{Perspectivas Futuras}

Outras interpelações abrangendo determinados detalhes técnicos ou ativos intelectuais específicos podem ainda serem realizadas em demandas futuras, enriquecendo a temática.

Uma opção de continuidade pode ser verificada por meio de pesquisas contemplando estudos quantitativos de casos e/ou decisões judiciais, por exemplo, levantando-se e analisando-se um percentual de sentenças que mencionaram as conclusões periciais. 
Um ponto ainda a ser desenvolvido pode versar sobre a metodologia empregada pelo perito durante a produção da prova pericial, fazendo um levantamento das atividades realizadas e do material utilizado por diferentes profissionais.

Outra aprendizagem pode ser obtida por meio de uma avaliação da evolução temporal da prova pericial, contrastando ações judiciais antigas com outras mais recentes, traçando um paralelo entre as questões que foram alteradas e de como foi sua evolução, sendo o caso.

\section{Referências}

AGUILLAR, Rafael S. S. R. A nova disciplina da prova pericial no Código de Processo Civil de 2015 e seu Impacto nos litígios de propriedade intelectual - parte II. Revista da ABPI, [s.l.], n. 141, p. 21-37, mar.- abr. 2016.

ALBERTO FILHO, Reinaldo Pinto. Da perícia ao perito. Niterói: Impetus, 2008.

ALMEIDA, Josimar Ribeiro de; OLIVEIRA, Simone Gomes de; PANNO, Marcia. Perícia ambiental. Rio de Janeiro: Thex, 2000.

ALVES, Enio Gomes. A percepção dos contadores sobre a importância da perícia contábil nas decisões judiciais. 2011. 27p. Artigo (Bacharelado em Ciências Contábeis) - Universidade Federal de Rondônia, Cacoal, 2011.

AVELINO, Murilo T. O controle judicial da prova técnica e científica. 2016. 254p. Dissertação (Mestrado) - Programa de Pós-Graduação em Direito do Centro de Ciências Jurídicas, Faculdade de Direito do Recife da Universidade Federal de Pernambuco, Recife, 2016.

BRASIL. Lei n. 9.279 de 14 de maio de 1996. Regula direitos e obrigações relativos à propriedade industrial. Diário Oficial [da] República Federativa do Brasil, Brasília, DF, 15 maio 1996.

Disponível em: http://www.planalto.gov.br/ccivil_03/Leis/L9279.htm. Acesso em: 8 jun. 2019.

BRASIL. Lei n. 13.105 de 16 de março de 2015. Código de Processo Civil. Diário Oficial [da] República Federativa do Brasil, Brasília, DF, 17 mar. 2015. Disponível em: http://www.planalto. gov.br/ccivil_03/_ato2015-2018/2015/lei/113105.htm. Acesso em: 8 jun. 2020.

BUSTAMANTE, Rogério Silva de. A prova pericial de engenharia no processo cível: fundamentos e prática. 2. ed. Rio de Janeiro: Forense, 1996.

DIDIER JUNIOR, Fredie; BRAGA, Paula Sarno; OLIVEIRA, Rafael Alexandria de. Curso de direito processual civil: teoria da prova, direito probatório, decisão, precedente, coisa julgada e tutela provisória. 10. ed. Salvador: JusPODIVM, 2015. v. 2.

FREITAS FILHO, Roberto; LIMA, Thalita Moraes. Metodologia de análise de decisões. Universitas Jus, Brasília, DF, n. 21, p. 1-17, jul.-dez. 2010. Disponível em: https://edisciplinas.usp.br/pluginfile. php/4318159/mod_resource/content $/ 1 /$ metodologia\%20de\%20analise\%20de\%20decisoes.pdf. Acesso em: 2 maio 2020.

GIL, Antonio Carlos. Métodos e técnicas de pesquisa social. 6. ed. São Paulo: Atlas, 2008.

MARINONI, Luiz Guilherme; ARENHART, Sérgio Cruz. Prova e convicção. São Paulo: Revista dos Tribunais, 2015. 
MARQUES, José Frederico. Manual de direito processual civil. Campinas: Bookseller, 1997.

MARTINS, Samir José Caetano. A prova pericial civil. Salvador: JusPodivm, 2008. v.1.

OLIVEIRA, Emerson Ademir Borges de; OLIVEIRA, Ademir de. A prova pericial contábil e os crimes fiscais. RDIET, Brasília, DF, v. 12, n. 1, p. 391-415, jan.-jun. 2017.

ROCHA, Fabiano de Bem da. Novos temas de processo civil na propriedade industrial. Rio de Janeiro: Kazsnar Leonardos, 2013. Disponivel em: https://www.kasznarleonardos.com.br/files/ Novos_Temas_de_Processo_Civil_na_Propriedade_Industrial.pdf. Acesso em: 11 abr. 2020.

STJ - SUPERIOR TRIBUNAL DE JUSTIÇA. AREsp 1161233 SP 2017/0216648-9. Relator: Min. Marco Aurélio Bellizze. Publicação: DJ 5/10/2017. Disponível em: https://ww2.stj.jus.br/ processo $/$ revista/documento/mediado/?componente $=$ MON\&sequencial $=77046653 \&$ tipo documento $=$ documento $\&$ num_registro $=201702166489 \&$ data $=20171005 \&$ formato $=$ PDF. Acesso em: 16 maio 2020.

STJ - SUPERIOR TRIBUNAL DE JUSTIÇA. REsp: 1726227 SP 2017/0150725-6. Relator: Min. Marco Aurélio Bellizze. Julgamento: 5/06/2018. Órgão Julgador: 3ª Turma. Publicação: DJe 8/06/2018. Disponível em: https://ww2.stj.jus.br/processo/revista/documento/mediado/?componen te $=I T A \&$ sequencial $=1719315 \&$ num_registro $=201701507256 \&$ data $=20180608 \&$ formato $=$ PDF. Acesso em: 16 maio 2020.

TJPR - TRIBUNAL DE JUSTIÇA DO PARANÁ. Ag PR 1256284-0 (Acórdão). Relator: Victor Martim Batschke. Julgamento: 10/2/2015. Órgão Julgador: 7. Câmara Cível. Publicação: 27/2/2015. Disponível em: https://portal.tjpr.jus.br/jurisprudencia/j/11841646/ Ac\%C3\%B3rd\%C3\%A3o-1256284-0. Acesso em: 16 maio 2020.

TJPR - TRIBUNAL DE JUSTIÇA DO PARANÁ. APL 11710793 (Acórdão). Relator: Luiz Antônio Barry. Julgamento: 15/3/2016. Órgão Julgador: 7a Câmara Cível. Publicação: DJ 1769 30/3/2016. Disponível em: https://portal.tjpr.jus.br/jurisprudencia/j/12118364/ Ac\%C3\%B3rd\%C3\%A3o-1171079-3\#. Acesso em: 15 maio 2020.

TJPR - TRIBUNAL DE JUSTIÇA DO PARANÁ. Sentença Conjunta PR 0014128-

35.2009.8.16.0019. Magistrada: Daniela Flavia Miranda. Órgão Julgador: $1^{\text {a }}$ Vara Cível. Publicação: 16/8/2019. Disponível em: https://projudi.tjpr.jus.br/projudi_consulta/arquivo.do?_tj=8a6 c53f8698c7ff7e57a8effb7e252198edfaa34abbf05e6628807eadaf8d25de9dd0b0b975d50f7. Acesso em: 10 jun. 2020.

ZARZUELA, José Lopes; THOMAZ, Pedro Lourenço; MATUNAGA, Minoru. Laudo pericial: aspectos técnicos e jurídicos. São Paulo: Revista dos Tribunais, 2000.

\section{Sobre os Autores}

\section{Arnoldo Reinaldo Richter Filho}

E-mail: arnoldinhofilho@gmail.com ORCID: http://orcid.org/0000-0002-4045-8783

Mestre em Propriedade Intelectual e Transferência de Tecnologia para Inovação pela Universidade Federal do Paraná em 2020.

Endereço profissional: Rua Theodoro Makiolka, n. 1.720, Curitiba, PR. CEP: 82640-010. 


\section{Marcelo Conrado}

E-mail: marceloconrado@hotmail.com

ORCID: http://orcid.org/0000-0002-4002-2613

Doutor em Direito das Relações Sociais pela Universidade Federal do Paraná em 2013.

Endereço profissional: Faculdade de Direito, Praça Santos Andrade, $1^{\circ}$ andar, Centro, Curitiba, PR. CEP: 80020-300. 